\title{
MARCIA BELISARDA, UN ENIGMA DEVELADO
}

\author{
MARTINA VINATEA RECOBA
}

Universidad del Pacífico vinatea_rm@up.edu.pe

RESUMEN: El propósito de este artículo es presentar cómo la debida investigación archivística ha servido para identificar la identidad de una escritora toledana del siglo XVII: Marcia Belisarda. Es evidente que, en los últimos años, el estudio de las escritoras de la Edad Moderna en el mundo hispánico ha experimentado un llamativo desarrollo desde distintos ámbitos: literario, histórico, bibliográfico, cultural o artístico. Sin embargo, aún queda mucho por hacer: resulta prioritaria la tarea de búsqueda en diferentes bibliotecas y archivos de manuscritos e impresos que contribuyan a ampliar el corpus de obras existentes, sobre todo si pensamos en que muchas de las obras escritas por mujeres no se imprimieron, sino que circularon en forma manuscrita dentro de un circuito de consumo de literatura conventual y comunitaria.

PALABRAS CLAVE: Marcia Belisarda; María de Santa Isabel; poesía lírica; monjas; escritura conventual. 


\section{MARCIA BELISARDA: A MYSTERY UNCOVERED}

ABSTRACT: The aim of this article is to examine how archival research has served to identify a seventeenth-century writer from Toledo, Marcia Belisarda. Evidently, in recent years the study of early modern writers in the Hispanic world has benefitted from major developments in different fields: literary, historical, bibliographical, cultural and artistic. Nevertheless, there is still much to be done and research in libraries and archives is of paramount importance so as to locate manuscripts and documents that expand the corpus of existing works. This is especially so if we think that many works written by women were not printed but circulated in manuscript form within a circle of consumption of conventual and religious community literature.

KEY WORDS: Marcia Belisarda, seventeenth-century religious writings, female religious, lyric poetry, convent writing.

$\mathrm{E}^{s}$ evidente que, en los últimos años, el estudio de las escritoras de la Edad Moderna en el mundo hispánico ha experimentado un llamativo desarrollo desde distintos ámbitos: literario, histórico, bibliográfico, cultural y artístico. Sin embargo, aún queda mucho por hacer: resulta prioritaria la tarea de búsqueda en diferentes bibliotecas y archivos de manuscritos e impresos que contribuyan a ampliar el corpus de obras existentes, sobre todo si pensamos en que muchas de las obras escritas por mujeres no se imprimieron, sino que circularon en forma manuscrita dentro de un circuito de consumo de literatura conventual y comunitaria. En el caso de la escritura femenina, además, se debe contribuir a la identificación de la autoría de muchas obras que, como en el caso de aquellas producidas en los conventos, han circulado designadas por un seudónimo o, en el mejor de los casos, por el nombre religioso.
El propósito de este artículo es presentar cómo la debida investigación archivística ha servido para identificar la identidad de una escritora toledana del siglo XVII: Marcia Belisarda. Para ello, se ha empleado una metodología harto conocida, pero sobre la que nunca está de más insistir:

1. Partir siempre del texto mismo. El texto ofrece la información más fidedigna y más segura.

2. Trabajar siempre de la mano de la historia que, en el caso que se presentará, ha sido determinante para el planteamiento de la hipótesis de autoría.

3. Realizar investigación en archivos, donde existe mayor información de la que podría imaginarse.

Marcia Belisarda fue una importante poeta toledana cuyo manuscrito poético se encuentra en la Biblioteca Nacional de España ${ }^{1}$ y su bibliografía puede consultarse en BIESES ${ }^{2}$. Es una importante autora que ha sido estudiada y editada parcialmente. Como es habitual en el caso de las religiosas, Marcia Belisarda escribe en el ámbito acotado de un convento que representa un espacio de ambigüedad entre el espacio público y el privado, pues "por un lado protege a la escritora como voz privada en su acto de emisión, pero por otro lado crea unas condiciones de difusión que permiten que, sin intervención aparente de la emisora, el escrito se haga público" (Baranda, 2005: 141-142). A muchas religiosas, como Marcia Belisarda, el ámbito acotado del convento les ofrece mayores posibilidades para la escritura y también les brinda un circuito de intercambio de sus composiciones. En este sentido, compartimos la afirmación de Isabel Barbeito, quien asegura que "las monjas intercambiaban poesías y otros escritos de mayor enjundia, tanto de autoría masculina como femenina, en gran parte manuscritos" (Barbeito, 2007: 68). Muchas veces, las monjas, avaladas por una bien cimentada fama espiritual, representaban modelos

${ }^{1}$ Signatura Ms. 7469, accesible en la Biblioteca Digital Hispánica.

${ }^{2}$ BIESES: Bibliografía de escritoras españolas/ Bibliography of Spanish Women Writers. Publicación en web: http://www.bieses.net

UNED. REI, 3 (2015), pp. 9-23

ISSN 2340-9029 
que otras monjas imitaban. Así componen relaciones, biografías, autobiografías, obras doctrinales, poesía, teatro y epistolarios. También debe reconocerse que la elección de escribir por convicción personal resulta una confesión de habilidad, de capacidad expresiva, de fijar en la memoria determinadas experiencias o conocimientos vinculados con la vida religiosa o vivencias espirituales. Esta poesía se conserva en manuscritos, pocas veces se edita y, cuando llega a la imprenta, generalmente es porque la obra es reconocida por la comunidad intra y extramuros. Asimismo, la obra poética en mención suele ser una edición póstuma. Así la monja no caía en el pecado del orgullo que podría acarrear la divulgación y notoriedad de su poesía (Graziosi, 1996: 303-331).

El trabajo se inició con la transcripción del manuscrito de la poesía de Marcia Belisarda, sobre el cual se preparó una edición anotada de la obra poética completa que acaba de ser publicada ${ }^{3}$ y donde también se ha aplicado la metodología antes mencionada que permitió trabajar una hipótesis de autoría.

Para comenzar, solamente se tenía un manuscrito, un seudónimo, un nombre de monja y la supuesta adscripción a un convento: el de las concepcionistas franciscanas. Los datos que aportaban los biógrafos, antologadores y comentaristas de la obra de Marcia Belisarda partían de la obra de la misma autora y se inician con Manuel Serrano y Sanz quien afirma lo siguiente:

Esta poetisa, una de las más fecundas del siglo XVII, fue monja según parece en el Real Convento de la Concepción de Toledo. Escribió sus versos con el seudónimo de Marcia Belisarda, bajo el cual los tenía dispuestos para publicarlos, deseosa de verlos reunidos; pero sus intentos no se lograron por causas que nos son desconocidas. De su biografía

\footnotetext{
${ }^{3}$ La edición anotada y el estudio preliminar de la poesía de Marcia Belisarda fue motivo de mi tesis doctoral, Estudio, edición y notas de la obra poética de Marcia Belisarda, dirigida por Nieves Baranda Leturio, Madrid: UNED, 2014; ahora publicada (Fernández López, 2015).
}

UNED. REI, 3 (2015), pp. 9-23 se sabe poco. Nació en Toledo, como lo da a entender el Licenciado Montoya en sus versos encomiásticos, y casi con seguridad a principios del siglo XVII. Impulsada, ya por vocación religiosa, ya por desengaños amorosos, de los que hay no pocas reminiscencias en sus versos, tomó el hábito de la Concepción de aquella ciudad fundado por la legendaria Beatriz de Silva. A los 27 años de su edad compuso sus primeros versos y entregada al cultivo de la poesía continuó haciendo otros muchos, ora religiosos y generalmente de poca inspiración; ora profanos y con más calor y vida que aquellos. Por el epígrafe de una de sus composiciones, vemos que vivía aún en el año 1646. Ignoramos la fecha de su fallecimiento (Serrano y Sanz, 1905: 362).

En la antología contenida en el libro Tras el espejo la musa escribe, Julián Olivares y Elizabeth Boyce se refieren a la escritora en términos parecidos a los de Serrano y Sanz (Olivares y Boyce, 1993: 327-390). Lo mismo ocurre con la introducción a la selección de poemas de Marcia Belisarda que realiza Ana Navarro en su Antología poética de escritoras de los siglos XVI y XVII (Navarro, 1989: 197-203).

La información que presenta Serrano y Sanz sobre el convento al que pertenecía María de Santa Isabel fue seguida sin más por los demás autores. Inclusive, hace algún tiempo, en el marco del congreso internacional Escritoras entre rejas. Cultura conventual femenina en la España moderna ${ }^{4}$, en las dos ponencias dedicadas a la obra de Marcia Belisarda, se refirieron a la autora como concepcionista, siguiendo a Serrano y Sanz.

Este importante bibliógrafo no aduce ninguna fuente documental para la identificación de la orden, así que parece probable que dedujo esa información de los poemas que dedica la autora a santa Beatriz de Silva, que por algún motivo llamaron su atención. Sin embargo, si revisamos el manuscrito de Marcia Belisarda, se observa que de

${ }^{4}$ UNED, Madrid, 5-7 de julio de 2012. Parte de los estudios presentados se publicaron en Baranda/ Marín (2014).

UNED. REI, 3 (2015), pp. 9-23

ISSN 2340-9029 
las 148 composiciones de la autora, solamente tres están dedicadas a santa Beatriz de Silva. Como figura individual, el mayor número de poemas de la colección está dedicado a Santiago, Patrón de España y de las Comendadoras de Santiago. Inclusive, en la rúbrica de uno de ellos se lee: "A nuestro patrón Santiago", único caso en el que la autora emplea un adjetivo posesivo para referirse a un santo. Por ello, y sin que consten otras informaciones que pudiera manejar Serrano y Sanz, se debe cuestionar su afirmación, ya que no existe razón alguna de peso para que adscribiera a Marcia Belisarda a alguna congregación.

Ahora bien, al trabajar la obra poética de la mencionada autora, consideramos indispensable plantear una hipótesis de autoría. Este deseo nos llevó a buscar la mayor cantidad de datos posibles para responder plausiblemente a ese problema. Como suele suceder en este tipo de indagaciones, se unieron la investigación archivística y la buena fortuna. Para recabar información, en primer lugar, tomamos contacto con el convento de la Concepción Francisca, con la esperanza de que tuvieran algún documento vinculado con sor María de Santa Isabel. Nos respondieron que, por diversas razones (suponemos que se refería a la desamortización de Mendizábal y a la guerra civil) no conservaban más que unos pocos documentos, pero que no nos serían de utilidad pues no se referían a la monja buscada. Paralelamente, escribimos a los archivos Provincial, de la Real Fundación de Toledo y de la Diputación y en las tres instituciones nos aseguraron que tenían alguna información que podría interesarnos. Con esta certeza, partimos a Toledo y empezamos las pesquisas en libros y documentos de las mencionadas instituciones. En muchas de las publicaciones leídas, observamos que una información se repetía: el palacio de Galiana albergó durante los siglos XVI y parte del XVII a dos congregaciones, las Concepcionistas Franciscas y las Comendadoras de Santiago. Esta información, unida a los poemas dedicados a Santiago que forman parte del poemario, nos hicieron despertar la idea de que Marcia Belisarda pudiera no haber sido monja de la Concepción Francisca, sino de las Comendadoras de Santiago. Por ello, consideramos pertinente visitar el convento de las Comendadoras en busca de alguna pista.

En el convento, la madre a cargo del archivo nos dijo que conservaban algunos "papeles antiguos" y pedimos se nos permitiera revisarlos. Así lo hicimos y en medio de centenares de documentos, encontramos un manuscrito sobre la vida de una monja del convento, fechado en 1664. La sorpresa fue que esta biografía había sido escrita por otra monja comendadora llamada María de Santa Isabel, ¿homónima de la autora cuyos escritos poéticos habíamos estado trabajando? A partir de este hallazgo, seguimos nuestras investigaciones en el archivo conventual para ver si encontrábamos otros datos sobre la mencionada religiosa y hallamos un expediente de limpieza de sangre que para poder ingresar al convento fue presentado por quien después sería María de Santa Isabel. Teníamos, entonces, por un lado el manuscrito de la obra poética procedente de la Biblioteca Nacional de España, cuya autora era una monja llamada María de Santa Isabel y cuyo seudónimo era Marcia Belisarda; una biografía de la madre María Bautista escrita por otra monja llamada María de Santa Isabel; y un expediente de limpieza de sangre presentado por quien después sería María de Santa Isabel. ¿Era la misma María de Santa Isabel en los tres casos? Debíamos verificar que las informaciones documentales casaran con los datos consignados en el poemario y, para nuestra alegría, lo hacían perfectamente.

Asimismo, nos cercioramos de que la letra del amanuense principal del poemario, la que copia los poemas desde el folio $6 \mathrm{r}$ hasta el $88 \mathrm{v}$ y que se ha supuesto la mano de la autora era la misma que escribió el manuscrito de la biografía de la venerable María Bautista; es decir, María de Santa Isabel o Marcia Belisarda. La comparación entre el manuscrito poético y el de la Vida de María Bautista evidenciaban similitudes caligráficas: el alargamiento de las letras "p", "q", "g" y las similitudes generales en la escritura: las " $d$ ", las " $y$ ", las "s" finales, el rasgo sobre la "i” son del mismo tipo. Además se pueden observar otras similitudes en la letra misma que llevan a asegurar sin duda alguna que ambos escritos fueron trazados por una misma mano. Efectivamente, la letra era la misma.

Finalmente, un poema, el $n^{\circ}$ 94, de Marcia Belisarda, dedicado a la traslación de una imagen de la Virgen, se puede explicar con un 
acontecimiento ocurrido en el convento de las Comendadoras y que está consignado en el manuscrito de la Vida de María Bautista:

En diferente imagen y muy pequeña habló la Virgen santísima a la madre M[arí]a Bautista, entrando a confesarse y subiendo los escalones del confesionario que así lo dijo a persona amiga y confidente que hoy vive y que le había dicho: '-Sácame de aquí- que soy la madre de Dios-', estando lejísimos el aposento donde la tenían del confesionario, a donde lo oyó $\mathrm{n}$ [uest]ra m[adr]e, la cual puso toda diligencia para que fuese tratada de allí adelante con mayor veneración como se ha hecho desde entonces en esta casa. (María de Santa Isabel, c. 1640: f. 42, r.)

\section{Poema 94}

A la traslación de una imagen de Nuestra Señora de una capilla a otra nueva, en su fiesta de la purificación, pidiéndome que se hiciese en la forma que el mismo villancico dirá el que se sigue

Hoy que la fiesta celebran

en que la reina divina

se purifica en el templo

siendo la pureza misma.

Hoy que ejemplo dando al mundo

la cándida flor María

el que nos dio fruto hermoso

ofrece a Dios por primicia.

Con afecto reverente,

la colocan a más rica

nueva mansión que en el templo

es vistosa maravilla.

De la antigua se despide,

porque si es razón que obliga

mudarse por mejorarse,

nunca más se verifica.
Dispensando inmensos rayos

de belleza peregrina

ya llega donde la cantan

las celestes jerarquías.

$\mathrm{Y}$ alegre se imitan,

sonoros se compiten,

volando por el aire

los serafines

dando, con dulces voces

la bienvenida

a la madre del sol, que es la aurora de nuestro día.

Ya en su regio solio entra y siguiendo a la capilla del cielo, la de la tierra, dicen con voces festivas:

Sea bienvenida

la aurora soberana

de nuestro día

todo brillo en su presencia

y todo a su hermosa vista

empíreo cielo parece

que las almas glorifica.

Sea bienvenida.

Los mayordomos insignes

de esta reina esclarecida

qué alcázar tan suntuoso

a su costa la fabrican

con espíritu bizarro,

con generosa hidalguía

en el clarín de la Fama,

y sus nombres eternizan.

Todos la reina festejen

y una y otra vez repitan:

«Sea bienvenida, 
Sea bienvenida

la que es dulce instrumento

de nuestras dichas».

$\mathrm{Y}$ alegre se imitan,

sonoros se compiten,

volando por el aire

los serafines

dando, con dulces voces,

la bienvenida

a la madre del sol, que es la aurora

de nuestro día. (Fernández López, 2015: 356-358)

Sobre la base de estas certezas, consideramos que existen fundadas razones para sostener que sor María de Santa Isabel, cuyo seudónimo literario fue Marcia Belisarda, fue monja en el convento de la Santa Fe de Toledo, ubicado en los Palacios de Galiana y que perteneció a la orden de las Comendadoras de Santiago y no a las Concepcionistas, como se había supuesto.

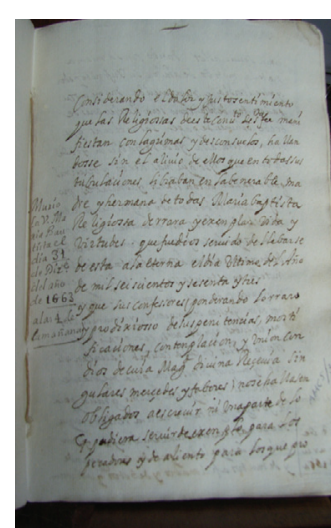

A todo lo anterior, se debe agregar que, hasta donde han podido alcanzar nuestras investigaciones, no existen datos sobre la existencia de alguna religiosa llamada María de Santa Isabel entre las concepcionistas ${ }^{5}$.

De este modo, la afirmación sobre la autoría de los textos se sustenta en el hecho real y

Imagen 1: Página del manuscrito de la Vida de María Bautista, Archivo de las Comendadoras de Santiago de Toledo, Manuscrito AMCS / 31, fotografía de la autora, reproducida con la generosa autorización de la Madre superiora de la congregación, Lucía González Girón.

${ }^{5}$ Esta información fue corroborada en las exposiciones de José Félix Duque y Connie Scarborough, quienes aseguraron que no hay rastros de una monja con el nombre de María de Santa Isabel en el convento de la Concepción francisca, en el Congreso internacional Escritoras entre rejas. Cultura conventual femenina en la España Moderna, Madrid, 5, 6 y 7 de julio de 2012.

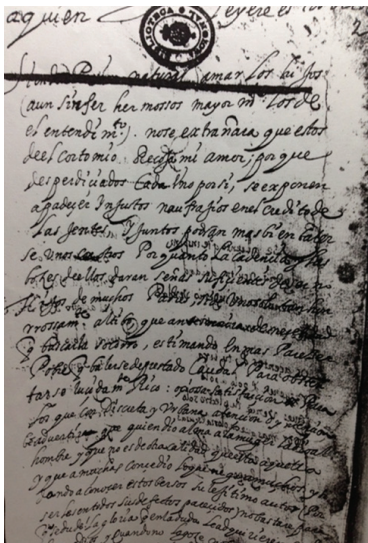

documentado de la existencia de una monja llamada María de Santa Isabel, que vivió en Toledo, en el convento de la santa Fe, en los años en que se escribió la colección de poemas cuyo manuscrito se encuentra en la BNE y en el hecho de que es autora de otra obra también manuscrita: Vida de la venerable madre María Bautista ${ }^{6}$. La hipótesis contempla que María de Santa Isabel, monja Comendadora de Santiago, fue la autora tanto del manuscrito de poesías como del manuscrito donde se relata la historia de la Imagen 2: Manuscrito de las venerable madre María Bautista, que se enpoesías de Marcia Belisarda, cuentra en el archivo de las Comendadoras Biblioteca Nacional de España, Mss. 7469, folio 2r. de Santiago, en Toledo.

La razón de la confusión de la orden a la que perteneció María de Santa Isabel se debe a que Serrano y Sanz lanzó una hipótesis basada en datos bastante endebles, pero que caló en la crítica. Tal como se sugería anteriormente, quizá el motivo que llevó a Serrano y Sanz a afirmar que Marcia Belisarda tomó el hábito en las concepcionistas fue el conjunto de poemas dedicados a santa Beatriz de Silva, su fundadora. Sin embargo, como ya se ha mencionado, las monjas concepcionistas y las Comendadoras de Santiago compartieron desde inicios del siglo XVI un mismo espacio: los Palacios de Galiana, en Toledo.

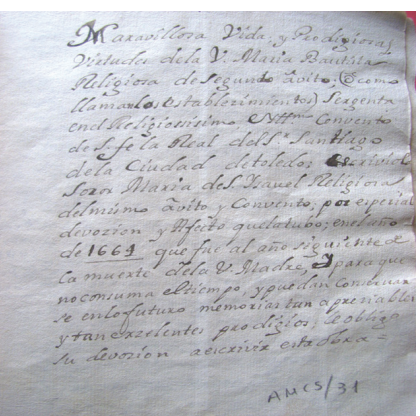

magen 3: Vida de María Bautista, portada, Archivo de las Comendadoras de Santiago de Toledo, Manuscrito AMCS / 31, foto de la autora, reproducida con la generosa autorización de la Madre superiora de la congregación, Lucía González Girón.

${ }^{6}$ El manuscrito se encuentra en el archivo de las Comendadoras de Santiago, en Toledo, bajo la signatura AMCS/31. 
En 1484, la reina Isabel la Católica cede una parte de los Palacios de Galiana y la capilla de la Santa Fe a Beatriz de Silva y doce mujeres devotas que la acompañaban. Esta decisión de la reina se debió a la admiración que sentía por la vida ejemplar de quien después sería santa Beatriz de Silva. El convento fundado por Beatriz de Silva ocupó la zona más próxima a la plaza de Zocodover, junto a la capilla de la santa Fe, por eso se llamó en un principio Convento de la Concepción de santa Fe. En el año 1502, los Reyes Católicos, administradores de las órdenes militares de Calatrava y de Santiago, trasladaron el convento de las Comendadoras de Santiago, que estaba en las montañas de santa Eufemia de Burgos, al alcázar de la reina en los palacios de Galiana. Así, se repartió el palacio del siguiente modo: una parte para el convento de la Concepción Francisca, que ya lo habitaba desde el año 1484; otra parte para el Hospital de niños expósitos que había pedido Cardenal Don Pedro González de Mendoza; y la mayor parte para el convento de las Comendadoras de Santiago (María de Santa Isabel, c. 1640) ${ }^{7}$.

El hecho de que compartieran un mismo espacio puede justificar la existencia de poemas de sor María de Santa Isabel dedicados a santa Beatriz de Silva, pero no es razón suficiente para su adscripción a la orden concepcionista. Basta considerar la existencia de un grupo grande de poemas dedicados a santos patronos de otros conventos toledanos.

Recuperar la identidad documental de Marcia Belisarda permite ofrecer un perfil biográfico a partir del expediente de limpieza de sangre ya mencionado. María de Santa Isa-

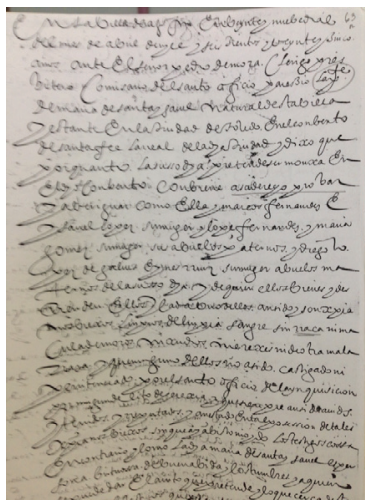

Imagen 4: Expediente de limpieza de sangre de sor María de Santa Isabel, Archivo de las Comendadoras de Santiago de Toledo, fotografía de la autora, reproducida con la generosa autorización de la Madre superiora de la lez Girón. congregación, Lucía Gonzá-

${ }^{7}$ En el manuscrito, se asegura que se guardan en el convento las cartas originales de los Reyes Católicos donde se explicita esta repartición. También véase García de Pesquera (1993). bel fue en el siglo María Fernández López, hija de Marcos Fernández e Isabel López. Sus abuelos paternos fueron Lope Fernández y María Gómez y sus abuelos maternos Diego López de Gálvez e Inés Ruiz. Tal como corresponde en los expedientes de limpieza de sangre, la postulante a monja presentó diez testigos que afirmaron que María de Santa Isabel y todos sus ancestros eran "cristianos viejos, personas honestas, nunca juzgadas por el tribunal del Santo Oficio y que no había en ellos rastro alguno de sangre mora o judía”.

De acuerdo con este documento y las fechas que aparecen en el poemario, María de Santa Isabel, natural de la villa de Ajofrín, ingresó al convento de la Santa Fe, a la congregación de las Comendadoras de Santiago, en 1625. El documento no ofrece ninguna fecha de nacimiento ni edad en la que profesó, pero si le asignamos un arco de tiempo frecuente para el ingreso al convento, entre 15 y 19 años, podemos suponer que Marcia Belisarda tenía alrededor de 27 años cuando redactó el manuscrito de poemas, fechado alrededor de 1640. Esta datación se ajusta a la edad que la escritora precisa en la rúbrica del primer poema; y por tanto tendría 51 años cuando escribió la Vida de María Bautista, fechada en 1664, las dos obras conocidas de la autora.

También conviene señalar que en el archivo de la Real Fundación de Toledo hallamos un documento que ofrece importante información sobre el abuelo materno de María de Santa Isabel, llamado Diego López de Gálvez, quien fue veedor y examinador del gremio de los tejedores de paño en la villa de Ajofrín (Paz Escribano et al, 1990: 416-417). Esto significa que tuvo categoría de "maestro" en su oficio. Se puede deducir de esta información que la familia de María de Santa Isabel pertenecía a la burguesía acomodada de la villa y que una familia así podría pretender un "mejor" convento que el de Nuestra Señora de la Descensión que había en la villa. Asimismo, esta prueba se refuerza con los indicios de una esmerada educación, a juzgar por la letra de la monja: cursiva, muy regular, usual en las personas cuya instrucción empezó en la infancia o ha tenido una larga práctica. Finalmente, en la Biblioteca Nacional de España, se encuentra el documento llamado "kalendario o martirologio Romano para el uso de las 
señoras Comendadoras de Santiago en el Monasterio de la Santa fe de Toledo" donde aparece información sobre las monjas comendadoras y anota que María de Santa Isabel murió en diciembre de 1665 (Marcos Burriel, 1757: 157).

Así, tomando siempre como punto de partida los textos, de la mano de la historia y con una mezcla de buena fortuna y búsqueda archivística se ha podido esbozar una hipótesis de autoría fehaciente: la biografía real y documentada de Marcia Belisarda, en la poesía; María de Santa Isabel, en el convento de las Comendadoras de Santiago; y ahora sabemos que también María Fernández López, en el siglo, natural de la Villa de Ajofrín y monja comendadora de Santiago en la ciudad de Toledo. La investigación ha permitido no solo desvelar el enigma de su identidad, sino que ha servido para marcar su origen y su perfil social y establecer la existencia de una obra literaria posterior. Con todo ello se enriquece sustancialmente el conocimiento de una de las poetas más relevantes del siglo de oro y se puede trabajar con mayor solvencia el manuscrito poético.

\section{Recibido: 02/12/2014}

Aceptado: 19/03/2015

\section{Referencias bibliográficas}

Baranda Leturio, Nieves (2005), Cortejo a lo prohibido. Lectoras y escritoras en la España moderna, Madrid: Arcolibros, pp. 141-142.

---; Marín Pina, Ma Carmen, eds. (2014), Letras en la celda. Cultura escrita de los conventos femeninos en la España moderna, Madrid, Ibero-Americana, Vervuert.

BIESES: Bibliografía de escritoras españolas/ Bibliography of Spanish Women Writers. Publicación en web:http://www.bieses.net

Barbeito Carneiro, María Isabel (2007), Mujeres y Literatura del siglo de Oro. Espacios profanos y espacios conventuales, Madrid: s.e.
Fernández López, María (Marcia Belisarda) (2015), Obra poética completa, ed. de Martina Vinatea, New York: Idea.

García de Pesquera, Eusebio (1993), “Orden de la Concepción: su identidad y novedad en los umbrales de la Edad Moderna”, en María Isabel Viforcos Marinas y Jesús Paniagua Pérez, coords. , I Congreso Internacional del monacato femenino en España, Portugal y América 1492-1992, II, León: Universidad, pp. 173-180.

Graziosi, Elisabetta (1996), "Scrivere in convento: devozione, encomio, persuasione nelle rime delle monache fra cinque e seicento", en Gabriella Zarri, ed., Donna, disciplina, creanza cristiana dal XVI al XVII secolo. Studi e testi a estampa, Roma: Edizioni di Storia e Letteratura, pp. 303-331.

Marcos Burriel, Andrés (1757), "Copia de la declaración jurada que dio el P. Andrés Marcos Burriel sobre la legitimidad de los instrumentos de doña Sancha Alfonso. Año 1757”, Biblioteca Nacional de España, Mss 13064, ff. 1r-17v.

María de Santa Isabel (c. 1640), Poesías, manuscrito, Biblioteca Nacional de España, Mss. 7469.

Navarro, Ana (1989), Antología poética de escritoras de los siglos XVI y XVII, Madrid: Castalia.

Olivares, Julián y Elizabeth Boyce (1993), Tras el espejo la musa escribe, Madrid: Siglo XXI editores.

Paz Escribano, Dolores de, José María Rodríguez Martín, Lourdes de la Cruz Palomino (1990), Historia de la villa de Ajofrín, Madrid: Recreativos Franco.

Serrano y Sanz, Manuel (1903-1905), Apuntes para una biblioteca de escritoras españolas desde el año 1401 al 1833, Madrid, Rivadeneyra. Digitalizada en BIESES: Bibliografía de escritoras españolas/ Bibliography of Spanish Women Writers, http://www.bieses.net 